\title{
Bajo un nuevo enfoque
}

\author{
Dr. Ismael Raudales \\ Director de Medicina Forense
}

\author{
https://doi.org/10.5377/rcfh.v5i1.8672
}

Soren Kierkegaard filósofo danés dijo que "La vida sólo puede ser vivida mirando hacia adelante", no hay opciones. Bajo un nuevo enfoque, sin descartar lo bueno, es necesario abrazar el futuro con esperanza, es por eso que en esta publicación de la Revista de Ciencias Forenses de Honduras arribamos a cinco años de existencia; bajo una nueva administración continuamos hacia adelante impulsando la publicación científica como herramienta para la validación de nuestra experticia, impulsando la investigación y docencia y promoviendo el debate científico.

En esta oportunidad se realiza una mirada crítica sobre los factores condicionantes que impiden la donación cadavérica en nuestro país, un tema que es de alta prioridad, no solo para la Dirección de Medicina Forense como actor clave en la generación de conocimiento y vinculación, sino para el país en general. Asimismo, se expone una revisión ética sobre el abordaje de este tema y los avances que en esta materia se realizan, mediante la propuesta de la creación del primer Banco de Córneas de Honduras. Compartimos algunos hallazgos interesantes que el día a día nos regala en el análisis cadavérico minucioso y responsable.

En esta administración de la Dirección de Medicina Forense apoyaremos decididamente la generación de pensamiento crítico, encaminado al fortalecimiento de nuestro quehacer diario, en coordinación con la Fiscalía General y Adjunta y la Escuela de Capacitación, propiciando las condiciones para que el camino recorrido continúe, se fortalezca y mejore, en aras de continuar con el compromiso de cumplir la misión, visión y filosofía institucional dictada por el Fiscal General de la República, en su planeación estratégica 2015-2020, que es, representar, defender y proteger los intereses de la sociedad hondureña a través de un ejercicio de reconocido prestigio, confianza y liderazgo.

Los invito a leer los interesantes contenidos que ponemos a su disposición. 